\title{
Biomass derived furfural-based facile synthesis of protected (2S)-phenyl-3-piperidone, a common intermediate for many drugs $\dagger$
}

50, 8324

Received 10th April 2014,

Accepted 1st May 2014

DOI: $10.1039 / c 4 c c 02645 d$

www.rsc.org/chemcomm

\author{
P.-F. Koh, ${ }^{a}$ P. Wang, ${ }^{a}$ J.-M. Huang ${ }^{\text {ab }}$ and T.-P. Loh ${ }^{\text {ac }}$
}

\begin{abstract}
An efficient synthetic route towards tosyl-protected (2S)-phenyl-3piperidone, a common intermediate for many drugs, has been developed in 5 steps in $54 \%$ yield from biomass derived furfural. The synthetic utility of the piperidone core structure was demonstrated with the synthesis of a $\mathrm{NK}_{1}$ receptor antagonist.
\end{abstract}

The sustained increase in the consumption of finite fossil fuel resources has painted a bleak global energy outlook for the 21st century. This has also attracted considerable research attention to various renewable resources such as biomass, which has the potential to serve as a renewable source of energy and organic carbon. ${ }^{1}$ Furfural 1 is a platform chemical which can be derived from biomass ${ }^{2 a, b}$ and annually about 300000 tonnes of agricultural raw materials are dehydrated to form furfural. It is notable that a recent report suggests a possible significant reduction in furfural production $\operatorname{costs}^{2 c}$ which highlights the potential for lower costs when utilizing furfural as a carbon source. The inclusion of furfural as one of the top "biobased product opportunities",3a emphasizes its usefulness in various domains such as fuels, ${ }^{3 b}$ solvents, ${ }^{3 c}$ natural product synthesis ${ }^{3 d-i}$ and more recently as chiral inducers. ${ }^{3 j}$ Annual world production of rice exceeds 500 million tonnes $^{4 a}$ and its associated agricultural waste, rice straw, is produced in large quantities in Asian countries such as China (110 Mt per year), India (97 Mt per year), Thailand (22 Mt per year) and the Philippines (11 Mt per year). ${ }^{4 b, c}$ Currently rice straw is largely left uncollected in the field or is disposed of through openfield burning which causes air pollution and health hazards. ${ }^{4}$

\footnotetext{
${ }^{a}$ Division of Chemistry \& Biological Chemistry, Nanyang Technological University, 50 Nanyang Avenue, Singapore 639798, Singapore

${ }^{b}$ School of Chemistry and Chemical Engineering, South China University of Technology, Guangzhou, Guangdong, 510640, China

${ }^{c}$ Hefei National Laboratory for Physical Sciences at the Microscale and Department of Chemistry, University of Science and Technology of China, Hefei, 230026, P. R. China. E-mail: teckpeng@ntu.edu.sg

$\dagger$ Electronic supplementary information (ESI) available: Additional text with full experimental details, characterization and crystallographic data, chromatograms and NMR spectra. CCDC 917485-917489. For ESI and crystallographic data in CIF or other electronic format see DOI: 10.1039/c4cc02645d
}

We envisioned that the xylan content present in rice straw could be used as a feedstock to produce furfural which can then be efficiently transformed into a tosyl-protected (2S)-phenyl-3piperidone core structure 2 which allows facile access to numerous neurokinin-1 ( $\left.\mathrm{NK}_{1}\right)$ receptor antagonists (Fig. 1). These potent $\mathrm{NK}_{1}$ receptor antagonists showed promising biological activities which may offer novel cures to disorders such as depression, anxiety and emesis. ${ }^{5}$ Various protected 2-phenyl-3-piperidones have been synthesized by Merck and other research groups with low overall yields $(<40 \%)$ over a minimum of 6 steps. ${ }^{6,7}$ The advantages of this strategy include the use of a cheap and renewable biomassderived starting material, being a short synthetic route with only a single silica gel column chromatography step, and obtaining product in a higher yield than existing methods with almost no loss of optical purity.

Modification of a previously reported synthesis of furfural 1 from corn $\operatorname{cobs}^{8}$ to rice straw with hourly removal of DCM from

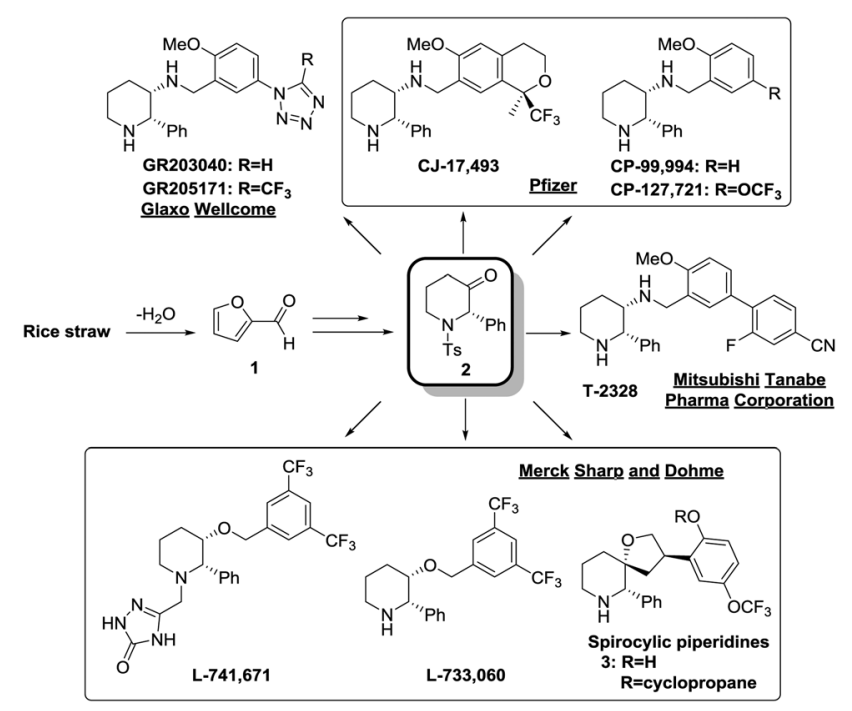

Fig. 1 Construction of the piperidone core structure from furfural to access various potent $\mathrm{NK}_{1}$ receptor antagonists. 


$$
\text { Rice straw } \frac{10 \mathrm{wt} \% \text { aq. } \mathrm{H}_{2} \mathrm{SO}_{4}}{\text { reflux, Dean Stark, } 8 \mathrm{~h}} \times 100 \%
$$

Scheme 1 Synthesis of furfural from rice straw.
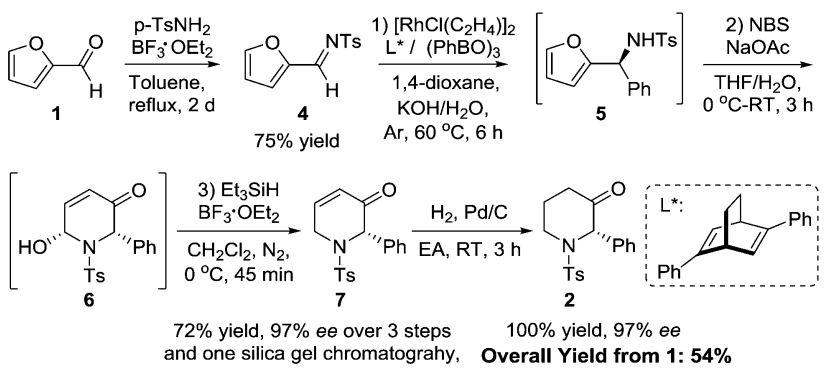

Scheme 2 Facile synthesis of piperidone $\mathbf{2}$ from biomass-derived furfural.

the Dean Stark trap gave a yield of $8.1 \mathrm{wt} \%$ without optimization (Scheme 1). The crude product obtained was found to be sufficiently pure without the need for further purification and could be transformed into imine 4 in the presence of 4-methylbenzenesulfonamide and a Lewis acid catalyst with a recrystallization yield of $75 \%$ (Scheme 2). Imine 4 was then subjected to a rhodium-catalyzed asymmetric arylation methodology developed by Hayashi's group ${ }^{9}$ to afford furylamine 5 with $97 \%$ yield and $99 \%$ enantiomeric excess (ee) after column chromatography. In view of the efficiency of this step, subsequent reactions were not subjected to chromatographic purification and crude 5 was able to undergo the aza-Achmatowicz rearrangement ${ }^{10}$ with $\mathrm{N}$-bromosuccinimide (NBS) as the oxidant to yield hemiaminal $\mathbf{6}$ as a cis diastereomer, as determined by NMR analysis and single-crystal X-ray crystallography ${ }^{11}$ (Fig. 2), probably as a result of an anomeric effect. The phenyl substituent at the chiral centre in rac-6 adopts a pseudoaxial orientation due to $\mathrm{A}^{1,3}$-strain ${ }^{12}$ with the tosyl protecting group. The aza-Achmatowicz rearrangement is a variation of the Achmatowicz rearrangement where the former involves an amine functional group as a nucleophile and the latter an alcohol. Crude 6 was able to be immediately reduced ${ }^{13}$ without further purification to give 7 in $72 \%$ yield and $97 \%$ ee over 3 steps from 4.7 was hydrogenated using $\mathrm{Pd} / \mathrm{C}$ in a quantitative conversion to yield tosyl-protected (2S)-phenyl-3-piperidone 2 . Thus, key intermediate

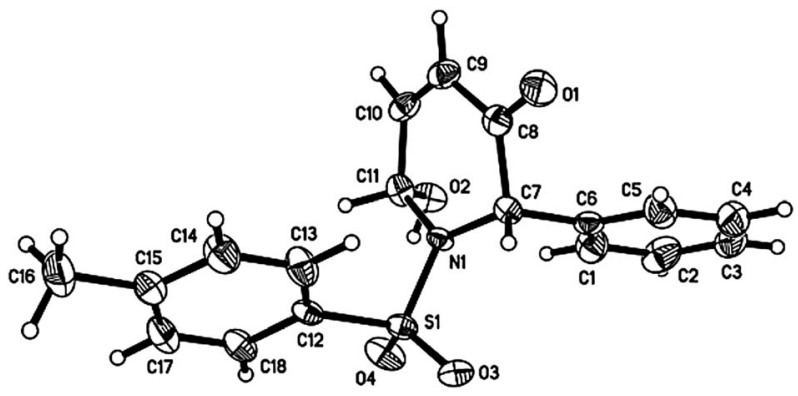

Fig. 2 ORTEP drawing of rac-6.



Fig. 3 ORTEP drawing of $\mathbf{7}$.

2 was efficiently synthesized in an overall yield of $54 \%$ over 5 steps from rice straw-derived furfural 1.

The optical rotation obtained for 7 is $[\alpha]_{\mathrm{D}}^{21}=+123(c=1.32$, $\mathrm{CH}_{2} \mathrm{Cl}_{2}$ ) for $97 \%$ ee while that reported in the literature ${ }^{7 c}$ is $[\alpha]_{\mathrm{D}}^{20}=-145\left(c=0.3, \mathrm{CH}_{2} \mathrm{Cl}_{2}\right)$, and the optical rotation obtained for 2 is $[\alpha]_{\mathrm{D}}^{23}=-10.0\left(c=1.01, \mathrm{CH}_{2} \mathrm{Cl}_{2}\right)$ for $97 \%$ ee while that reported in the literature ${ }^{7 c}$ is $[\alpha]_{\mathrm{D}}^{20}=+5\left(c=0.2, \mathrm{CH}_{2} \mathrm{Cl}_{2}\right)$. The absolute structure of 7 was determined using single-crystal X-ray crystallography ${ }^{11}$ (Fig. 3), and further HPLC analysis of the particular single-crystal used in the X-ray crystallography as well as the batch of crystals submitted for analysis showed retention times and an elution order that were in agreement with those of experimentally obtained values (see ESI $\dagger$ for more details). This rules out the possibility that the structure obtained from the single-crystal X-ray crystallography is the minor enantiomer and hence it can be concluded that the experimentally obtained 7 is indeed the desired $(S)$-2-phenyl-1tosyl-1,6-dihydropyridin-3(2H)-one. This conclusion can be further extended to assign the absolute configuration of 2 as (S)-2-phenyl-1-tosylpiperidin-3-one. The loss of ee was subsequently determined to be due to the inherent acidity of the silica gel chromatography; pre-treatment of silica gel with $1 \%$ triethylamine also resulted in a loss of ee while recrystallization attempts proved to be futile. The acid and base sensitivity of 2 and 7 may be attributed to the lability of the $\alpha$-hydrogen at the chiral centre.

$\mathrm{NK}_{1}$ receptor antagonist 3 was synthesized to illustrate the synthetic utility of piperidone 2 (Scheme 3). Rac-2 was able to undergo a Grignard reaction and subsequent TMS deprotection step to form $r a c-8$, which was immediately subjected to SearlesCrabbé homologation ${ }^{14}$ conditions without further purification to transform the alkyne moiety to an allene rac-9 in $69 \%$ yield over 3 steps. The relative stereochemistry in $\mathbf{r a c}-\mathbf{8}$ was established using single-crystal X-ray crystallography ${ }^{11}$ where the alkyne is trans to the phenyl substituent. The preference for the pseudoaxial orientation of the phenyl substituent in rac-2 gives rise to a single diastereomer in the Grignard reaction due to the steric hindrance imposed by the phenyl substituent on one face of the carbonyl group.

Au-catalyzed cycloisomerisation ${ }^{15}$ of rac-9 constructed the spirocycle $r a c-10$ in $85 \%$ yield and $r a c-10$ was analyzed with 


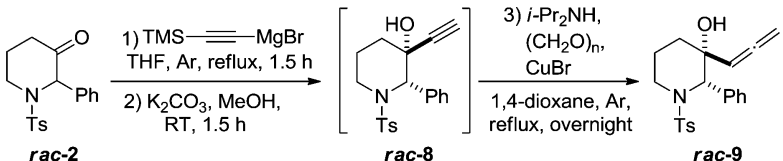

rac-8 $69 \%$ yield over 3 steps
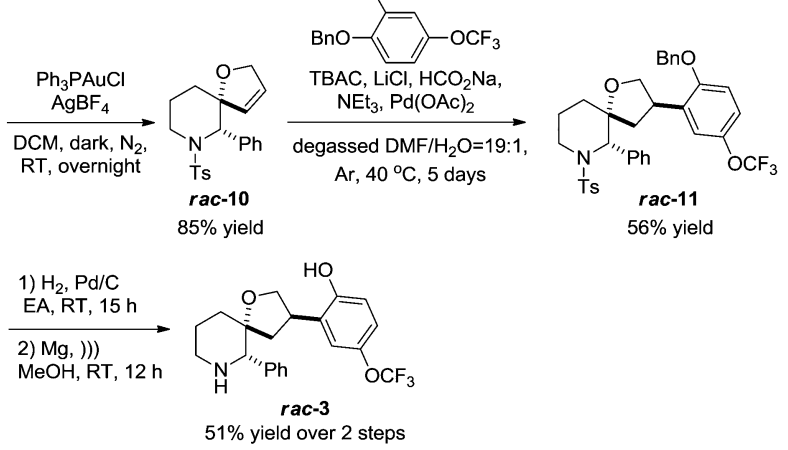

Scheme 3 Synthesis of rac-3 using a Searles-Crabbé homologation, $\mathrm{Au}$-catalyzed cycloisomerisation and reductive Heck reaction.

single-crystal X-ray crystallography. ${ }^{11} \mathrm{~A}$ regio- and stereoselective reductive Heck reaction developed by Merck $^{6 b, c}$ transformed rac-10 to rac-11 in 56\% yield. The stereoselectivity of the reductive Heck reaction can be rationalized by the preferential approach of the arylpalladium species from the less hindered face of the dihydrofuran moiety in rac-10, while the regioselectivity arises due to steric considerations. ${ }^{16}$

The relative stereochemistry of $\mathbf{r a c}-\mathbf{1 1}$ was also confirmed using NOE analysis ${ }^{17}$ where the two benzylic protons in rac-11 were shown to have NOE correlations, in agreement with the results reported by Merck. Rac-11 was finally subjected to Pd-catalyzed hydrogenation and Mg-promoted tosyl deprotection with the help of sonication to complete the synthesis of rac-3 in $51 \%$ yield over 2 steps as a white solid instead of a pale yellow oil reported by $\operatorname{Merck}^{6 b}$ for the reported enantiopure form. The single-crystal X-ray crystal ${ }^{11}$ structure of rac-3 is shown (Fig. 4).

We have demonstrated the efficiency of synthesizing tosylprotected (2S)-phenyl-3-piperidone 2 , a common intermediate for many drugs, from rice straw-derived furfural 1 by employing Hayashi's highly enantioselective rhodium-catalyzed arylation methodology as well as the aza-Achmatowicz rearrangement



Fig. 4 ORTEP drawing of rac-3. reaction. This synthetic strategy has the advantage of being a shorter route with only a single silica gel chromatography step, generating product in higher yield with almost no loss of optical purity, and originating from a renewable source, thus improving its sustainability and alleviating the problems caused by the open-field burning of rice straw. Most importantly, 2 allows facile access to numerous biologically active compounds and its synthetic usefulness has been demonstrated with the synthesis of rac-3.

This research was supported financially by Nanyang Technological University (New Initiative Funding) and the National Environment Agency (NEA-ETRP Project Ref. No. 1002 111). The authors would like to thank Dr Ganguly (NTU) and Dr Li (NTU) for their assistance with the single-crystal X-ray crystallography.

\section{Notes and references}

1 (a) E. E. Hood, P. Nelson and R. Powell, Plant Biomass Conversion, Wiley-Blackwell, Chichester, 2011; (b) G. Centi and R. A. v. Santen, Catalysis for renewables: from feedstock to energy production, WileyVCH, Weinheim, 2007; (c) D. L. Klass, Biomass for renewable energy, fuels, and chemicals, Academic Press, San Diego, 1998.

2 (a) K. J. Zeitsch, The Chemistry and Technology of Furfural and its Many By-Products, Sugar Series, Elsevier, Amsterdam, 2000, vol. 13; (b) A. Corma, S. Iborra and A. Velty, Chem. Rev., 2007, 107, 2411-2502; (c) R. Xing, W. Qi and G. W. Huber, Energy Environ. Sci., 2011, 4, 2193-2205.

3 (a) J. J. Bozell and G. R. Petersen, Green Chem., 2010, 12, 539-554; (b) J.-P. Lange, E. van der Heide, J. van Buijtenen and R. Price, ChemSusChem, 2012, 5, 150-166; (c) F. W. Lichtenthaler and S. Peters, C. R. Chim., 2004, 7, 65-90; (d) P. Srihari and Y. Sridhar, Eur. J. Org. Chem., 2011, 6690-6697; (e) C. A. Leverett, M. P. Cassidy and A. Padwa, J. Org. Chem., 2006, 71, 8591-8601; $(f)$ M. P. Cassidy and A. Padwa, Org. Lett., 2004, 6, 4029-4031; $(g)$ J. M. Harris and A. Padwa, J. Org. Chem., 2003, 68, 4371-4381; (h) J. M. Harris and A. Padwa, Org. Lett., 2002, 4, 2029-2031; $(i)$ M. H. Haukaas and G. A. O'Doherty, Org. Lett., 2001, 3, 401-404; ( $j$ ) A. Kabro, E. C. EscuderoAdán, V. V. Grushin and P. W. N. M. van Leeuwen, Org. Lett., 2012, 14, 4014-4017.

4 (a) K. L. Kadam, L. H. Forrest and W. A. Jacobson, Biomass Bioenergy, 2000, 18, 369-389; (b) Q. Li, S. Hu, D. Chen and B. Zhu, Biomass Bioenergy, 2012, 47, 277-288; (c) B. Gadde, C. Menke and R. Wassmann, Biomass Bioenergy, 2009, 33, 1532-1546.

5 See $\mathrm{ESI} \dagger$ for a complete list of references for the $\mathrm{NK}_{1}$ receptor antagonists.

6 (a) P. E. Maligres, M. M. Waters, J. Lee, R. A. Reamer, D. Askin, M. S. Ashwood and M. Cameron, J. Org. Chem., 2002, 67, 1093-1101; (b) D. J. Wallace, J. M. Goodman, D. J. Kennedy, A. J. Davies, C. J. Cowden, M. S. Ashwood, I. F. Cottrell, U.-H. Dolling and P. J. Reider, Org. Lett., 2001, 3, 671-674; (c) J. J. Kulagowski, N. R. Curtis, C. J. Swain and B. J. Williams, Org. Lett., 2001, 3, 667-670.

7 (a) J. Lee, T. Hoang, S. Lewis, S. A. Weissman, D. Askin, R. P. Volante and P. J. Reider, Tetrahedron Lett., 2001, 42, 6223-6225; (b) C. G. Kokotos and V. K. Aggarwal, Chem. Commun., 2006, 2156-2158; (c) X. Gaucher, M. Jida and J. Ollivier, Synlett, 2009, 3320-3322; (d) N. M. Garrido, M. García, M. R. Sánchez, D. Díez and J. G. Urones, Synlett, 2010, 387-390; (e) M. Atobe, N. Yamazaki and C. Kibayashi, J. Org. Chem., 2004, 69, 5595-5607; $(f)$ O. Calvez and N. Langlois, Tetrahedron Lett., 1999, 40, 7099-7100; $(g)$ K. Takahashi, H. Nakano and R. Fujita, Tetrahedron Lett., 2005, 46, 8927-8930; (h) P.-Q. Huang, L.-X. Liu, B.-G. Wei and Y.-P. Ruan, Org. Lett., 2003, 5, 1927-1929; (i) L.-X. Liu, Y.-P. Ruan, Z.-Q. Guo and P.-Q. Huang, J. Org. Chem., 2004, 69, 6001-6009; (j) S. V. Pansare and E. K. Paul, Org. Biomol. Chem., 2012, 10, 2119-2125.

8 R. Adams and V. Voorhees, Org. Synth., 1941, 1, 280.

9 (a) N. Tokunaga, Y. Otomaru, K. Okamoto, K. Ueyama, R. Shintani and T. Hayashi, J. Am. Chem. Soc., 2004, 126, 13584-13585; (b) G. Berthon and T. Hayashi, Rhodium- and Palladium-Catalyzed Asymmetric 
Conjugate Additions, in Catalytic asymmetric conjugate reactions, ed. A. Córdova, Wiley-VCH, Weinheim, Germany, 2010, pp. 1-44.

10 (a) O. Achmatowicz Jr, P. Bukowski, B. Szechner, Z. Zwierzchowska and A. Zamojski, Tetrahedron, 1971, 27, 1973-1996; (b) E. A. Couladouros and M. P. Georgiadis, J. Org. Chem., 1986, 51, 2725-2727; (c) Review: M. A. Ciufolini, C. Y. W. Hermann, Q. Dong, T. Shimizu, S. Swaminathan and N. Xi, Synlett, 1998, 105-114; (d) Y. Lefebvre, Tetrahedron Lett., 1972, 13, 133-136; (e) Z.-H. Lu and W.-S. Zhou, J. Chem. Soc., Perkin Trans. 1, 1993, 593-596; $(f)$ Z. Wei-Shan, X. WenGe, L. Zhi-Hui and P. Xin-Fu, Tetrahedron Lett., 1995, 36, 1291-1294; (g) W.-S. Zhou, W.-G. Xie, Z.-H. Lu and X.-F. Pan, J. Chem. Soc., Perkin Trans. 1, 1995, 2599-2604; (h) L.-X. Liao, Z.-M. Wang, H.-X. Zhang and W.-S. Zhou, Tetrahedron: Asymmetry, 1999, 10, 3649-3657; (i) W.-S. Zhou, Z.-H. Lu, Y.-M. Xu, L.-X. Liao and Z.-M. Wang, Tetrahedron, 1999, 55, 11959-11983; $(j)$ H.-J. Altenbach and R. Wischnat, Tetrahedron Lett., 1995, 36, 4983-4984; ( $k$ ) J. C. P. Hopman, E. van den Berg, L. O. Ollero, H. Hiemstra and W. Nico Speckamp, Tetrahedron
Lett., 1995, 36, 4315-4318; (l) The mechanism for aza-Achmatowicz rearrangement is illustrated in the ESI $\dagger$.

11 The CIF files, ORTEP drawings and CCDC deposition numbers of the crystalline compounds are provided in the ESI $\dagger$.

12 (a) J. D. Brown, M. A. Foley and D. L. Comins, J. Am. Chem. Soc., 1988, 110, 7445-7447; (b) S.-e. Yoo and S. H. Lee, J. Org. Chem., 1994, 59, 6968-6972.

13 M. D. Lewis, J. K. Cha and Y. Kishi, J. Am. Chem. Soc., 1982, 104, 4976-4978.

14 S. Searles, Y. Li, B. Nassim, M.-T. R. Lopes, P. T. Tran and P. Crabbé, J. Chem. Soc., Perkin Trans. 1, 1984, 747-751.

15 B. Gockel and N. Krause, Org. Lett., 2006, 8, 4485-4488.

16 R. F. Heck, Palladium-Catalyzed Vinylation of Organic Halides, in Organic Reactions, ed. W. G. Dauben, John Wiley \& Sons Inc, New York, 1982, vol. 27, p. 345.

17 COSY, HMQC and nuclear Overhauser effect analyses are available in the ESI $\dagger$. 